\title{
Tissue reaction after subcutaneous implantation of a membrane composed of bacterial cellulose embedded with hydroxyapatite
} $\underset{\text { Kinoshita }^{1 *}}{\text { Kassari }}{ }^{1}$, Gilberto O. Marinho ${ }^{1}$, Jordan L. Silva ${ }^{1}$, Leandro A. Holgado ${ }^{1}$, Alcides L. Leão ${ }^{2}$, Marcia R. M. Chaves ${ }^{1}$ and Angela

${ }^{1}$ Universidade Sagrado Coração - USC, Bauru, São Paulo, Brazil

${ }^{2}$ Universidade Estadual Paulista - UNESP, Botucatu, São Paulo, Brazil

\begin{abstract}
A biomaterial that has been studied to compose bone substitutes is a bacterial cellulose (BC) obtained mainly from a gram-negative bacteria such as the Acetobacter xylinum culture (Gluconacetobacter xylinus). It is characterized by having high modulus of elasticity and tensile, high crystallinity due to the three-dimensional network of nanofibers and a large number of hydroxyl groups on the surface, allowing the synthesis of nanoparticles. Hydroxyapatite nanoparticles (Hap) can be synthesized in the $\mathrm{BC}$ matrix. Thus, it becomes a biomaterial $\mathrm{BC} / \mathrm{Hap}$ with a structure that resembles a bone and that can be used as a bone substitute. One of the first steps of new materials testing for clinical use consists of biocompatibility tests. Among them, there is the tissue response to subcutaneous implantation that provides important information about the general response of the body through the inflammatory pattern observed. Thus, the study of tissue response of BC/Hap is necessary and valuable for its future applications as a biomaterial for the bone reconstruction procedure. In this study, 18 male rats (Rattus norvegicus, Wistar) were used. Three incisions were surgically made in their backs for the subcutaneous implantation of materials to be tested: BC, BC/Hap and PTFE (polytetrafluoroethylene), which are recognized as biocompatible materials and are widely used as biomaterials. After 7, 15 and 60 days post-surgery, a number of 6 animals were submitted to euthanasia and the tissue reaction was analyzed microscopically. To compare the inflammatory pattern, the amount of mononuclear and polymorphonuclear cells was verified, as well as the presence of fibrous capsule. Quantitative data were evaluated according to a predetermined score and the comparison of the results was performed by means of the nonparametric Kruskal Wallis Test. There was no difference as to the inflammatory pattern of BC and BC/Hap materials when compared to PTFE ( $>$ >0.05), suggesting that $\mathrm{BC}$ and $\mathrm{BC} / \mathrm{Hap}$ can both produce the same tissue reaction as the PTFE.
\end{abstract}

\section{Introduction}

Bone defects can occur after surgeries, acute or chronic infections, trauma and/or congenital malformations, which represent a serious problem in medicine and dentistry. The defects that have greater amplitude, also called critical-size defects, represent a great challenge to the regenerative and reconstructive therapy [1] and usually require the use of bone substitutes and/or other treatments to reach the right repair. The traditional grafts include the autologous, when transplanted from one place to another in the same individual; the allogeneic, when transplanted between individuals of the same species but genetically different, and the xenogeneic, when obtained from a donor of another species [2,3]. All of them have advantages and disadvantages. The autologous are the gold standard but they are not always available and usually cause additional post-surgical pain [1]. Thus, several studies have been conducted in order to search for alternative materials that imitate the bone [4]. Biomaterials stand out because they are possibly the most versatile alternative among all others [5].

The bone is composed of a collagen matrix reinforced with hydroxyapatite crystals (Hap). Various biomaterials such as the collagen, cellulose and chitosan are used as a scaffold to control the distribution of apatite crystals in order to acquire the same structure found in the bone. In this context, the bacterial cellulose (BC) has called attention for being a renewable material, since it is produced by the fermentation of bacteria such as the Gluconacetobacer xylinus [6]. It consists of a three-dimensional network of cellulose nanofiber and it has a high coefficient of elasticity and tension. The large number of hydroxyl groups on the surface of BC permits the synthesis of nanoparticles. Therefore, many studies have been conducted to synthesize Hap nanoparticles in the BC-dimensional network to be used as bone substitutes $[7,8]$.

The biological effects of new biomaterials can be initially evaluated both in vitro and in vivo. The in vitro tests evaluate the properties of the materials directly in the cell culture, which reacts to them. Afterwards, the response is analyzed. The in vivo tests are based primarily on subcutaneous, intramuscular or bone implantation of the material in animals (rats, rabbits, etc.). After different periods of the material implantation, the adjacent tissue is examined macroscopically and microscopically. In the early post-implantation periods, the inflammatory response is the main feature to be analyzed. In the long term, the nature and amount of fibrous encapsulation is evaluated [9]. Inflammation is a response of the tissues to an injurious agent and it is

Correspondence to: Angela Kinoshita, Universidade Sagrado Coração, Rua Irmã Arminda 10-50 - Bauru - São Paulo - Brazil -17.011-160, Tel: +55-14-21077069, E-mail: angela.kinoshita@usc.br; angelamitie@gmail.com

Key words: bacterial cellulose, biocompatibility, biomaterial, bone regeneration, hydroxyapatite

Received: February 07, 2015; Accepted: March 23, 2015; Published: March 27, 2015 
characterized by fluid blood cells leaving the interstitium. This process is intended to eliminate the cause of aggression and induce the repair of dead cells and tissues by healthy cells [10].

The degree of success in the implementation of a biomaterial, in some cases, can be associated, for example, with the severity of the inflammatory process triggered, the patient satisfaction level, the time required for the establishment of the basic activities of the patient, the length of time for the implantation in the body, among others [5].

The healing process involves a complex sequence of cellular and biochemical events that are necessary to restore tissue integrity after injury. This process is characterized by homeostasis, inflammation, granulation tissue formation, epithelialization and remodeling of extracellular matrix [10]. During the inflammatory phase, the migration of cells such as the neutrophils, lymphocytes and macrophages is essential for regulating the repair process. These cells secrete cytokines and growth factors that act as molecular signaling. Neutrophils are the first inflammatory cell recruitment, appearing approximately 24 hours after the injury, having the functions of phagocytosis and debridement. Macrophages migrate to the wound site from about 48 to 96 hours, becoming the predominant cell population before the migration and proliferation of fibroblasts. An important contribution of macrophages in the healing process is the secretion of cytokines and the activation of pro-inflammatory enzymes, which activates and recruits other cells involved in the healing process such as the macrophages and other lymphocytes. It also regulates the proliferation of fibroblasts, promoting the synthesis collagen and stimulating the migration of endothelial cells, which are also involved in the tissue repair process $[11,12]$.

Different from in vitro studies, in vivo implantations provide information on the removal of substances from tissues and on the overall response of the organism to the implantation of new material through the inflammatory response. Therefore, this type of study is the nearest alternative to what will occur in the patient and it has been successfully used in several studies [11,13-15].

Therefore, this study investigates the tissue reaction to the biomaterial bacterial cellulose obtained by Gluconacetobacer xylinus embedded by hydroxyapatite, BC/Hap through subcutaneous implant on the back of rats for future use as a biomaterial for bone substitute.

\section{Material and methods}

Bacterial Cellulose $(B C)$ and Bacterial Cellulose embedded with Hydroxyapatite (BC/Hap)

Briefly, BC was synthesized by the bacteria Gluconacetobacter xylinus in culture medium at a temperature of $30^{\circ} \mathrm{C}$ for a period of 6 days, under static conditions in a $200 \mathrm{~mL}$ Erlenmeyer flask with $5 \%$ of the bacteria in culture medium. After this process, the membranes were washed and purified. The BC membrane was removed and washed with a $5 \%(\mathrm{w} / \mathrm{v})$ sodium hydroxide solution under heating at a temperature of $80^{\circ} \mathrm{C}$ for 30 minutes. This procedure was repeated 8 times until white colored cellulose was obtained. Additional washes with water from the tap were made subsequently, until the neutral $\mathrm{pH}$ was reached, and distilled water was used to remove salts.

Another bacterial cellulose membrane underwent a deposition process for the incorporation of hydroxyapatite in its composition. For this deposition, the membrane was kept in disodium phosphate solution $\left(60 \mathrm{mM} \mathrm{Na}_{2} \mathrm{HPO}_{4}\right)$ for 24 hours, it was washed with distilled water for the removal of salts and thereafter kept in a Calcium Chloride
$\left(\mathrm{CaCl}_{2} 100 \mathrm{mM}\right)$ solution for 24 hours. This process was carried out six times. Throughout the hydroxyapatite deposition, the membrane was left in a shaker (Tecnal, Brazil) at $360^{\circ}$ rotational movement at a temperature of $35^{\circ} \mathrm{C}$.

Both $\mathrm{BC}$ and $\mathrm{BC} /$ Hap membranes were dried in an oven (Medicate, Brazil) for 3 days at $50^{\circ} \mathrm{C}$. After that, they were cut in a circular shape with a diameter of $5 \mathrm{~mm}$ and sterilized with gamma radiation $(25$ $\mathrm{kGy}$ ) to be used in surgical procedures. Similarly, the PTFE membrane (Bionnovation, Brazil) was also cut and sterilized.

A fraction of each material was subjected to a scanning electron microscopy SEM and an energy dispersive spectroscopy (SEM/EDS) in order to observe the amount of carbon, calcium and phosphorus deposited on the membrane and on the sites that were deposited.

\section{Surgical procedure}

The present study was approved by the Ethical Committee of the Universidade Sagrado Coração - USC, Bauru, São Paulo State, Brazil and it was conducted according to recommendations set by the National Institute of Health (NIH) [16].

For the surgical procedure, the animals underwent anesthesia with the administration via IP of the muscle relaxant xylazine hydrochloride, $13 \mathrm{mg} / \mathrm{kg}$ body weight, (Anasedan-Vetbrands, Brazil) associated with the general anesthetic ketamine hydrochloride (Dopalen - Vetbrands, Brazil), $87 \mathrm{mg} / \mathrm{kg}$ body weight. Under the effect of anesthesia, the dorsal region was shaved and a $2 \%$ chlorhexidine gel was used in the antisepsis of the site. Then, each animal received three incisions of approximately $0.8 \mathrm{~cm}, 1 \mathrm{~cm}$ distant from each other, with a blade n. 15, followed by a dilatation with surgical scissors until the desired area to perform the implantation was reached. In each site, one type of material was implanted: BC or BC/Hap or PTFE. The suture of tissues was made with nylon (Shalon Nylon 4-0). After the surgical procedure, an antimicrobial $10 \mathrm{mg} / \mathrm{kg}$ (Enrofloxacin 2.5\%, FlotrilSchering Plough, Brazil) was applied once a day for 7 days and sodium dipyrone $25 \mathrm{mg} / \mathrm{kg}$ (D-500 Fort Dodge, Brazil) was applied once a day for 3 days.

After the observation periods of 7, 15 and 60 days post-surgery, the animals were euthanized by overdose of barbiturate thiopental $150 \mathrm{mg} /$ $\mathrm{kg}$ (Thiopentax ${ }^{\circledR}$, Cristalia, Brazil) associated with lidocaine $10 \mathrm{mg} / \mathrm{kg}$ (Xylestesin ${ }^{\circledR} \%$, Cristalia, Brasil).

\section{Microscopic analysis}

The excised samples containing the implanted material and adjacent tissues were preserved in $10 \%$ neutral buffered formalin for 48 hours. Then, the pieces were cut transversely in the direction of the diameter of the biomaterial, for a subsequent inclusion in paraffin and were prepared for a microscopic analysis following routine histology procedures. Sections with $6 \mu \mathrm{m}$ were stained with Hematoxilin and Eosin. A Nikkon H550L photomicroscope was used to get the images.

For the quantitative analysis, six areas, with a $40 \mathrm{X}$ magnification, were taken around the region of each material implantation, then used for counting the inflammatory cells: polymorphonuclear, mononuclear and giant cells using the software ImageJ [17]. The average of inflammatory cells for each specimen was ranked using the same parameters used by Yaltirik et al. [18], as follows: score 0 for 0 cells (no reaction); 1 for $<25$ cells (slight reaction); 2 for $25<$ to $<125$ cells (moderate) and score 3 for $>125$ cells (severe reaction). The comparison of the results was performed by the nonparametric Kruskal Wallis Test and the values were considered statistically different when $p<0.05$. 


\section{Results}

\section{Materials}

Figure 1 shows the SEM images of the PTFE (A), BC (B) and BC/Hap $(\mathrm{C}$ and $\mathrm{D})$ membranes. The images clearly show the functionalization of BC surface due to the Hydroxyapatite deposition.

Figure 2 shows the EDS analysis showing the distribution of

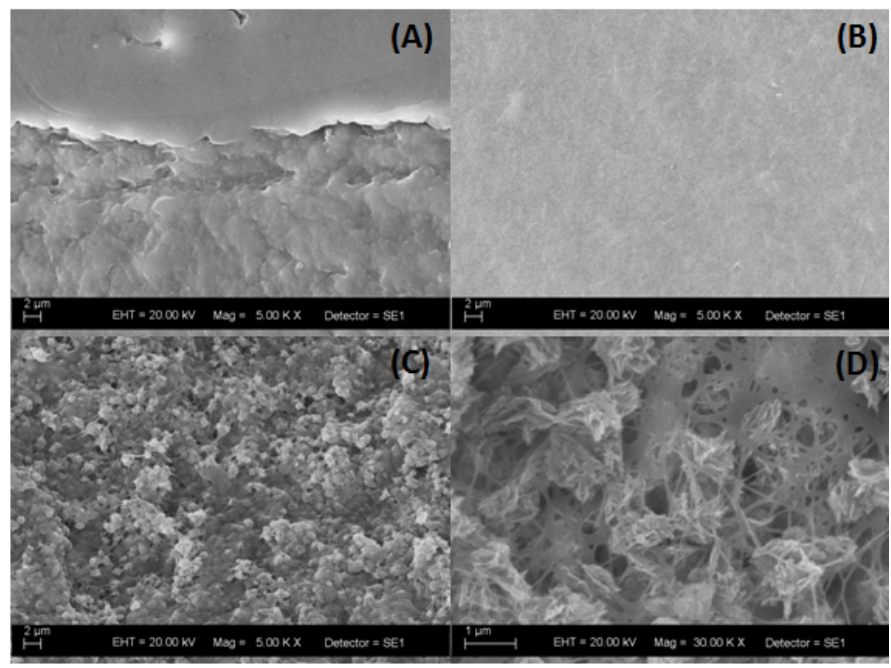

Figure 1. SEM images of (A) PTFE, (B) BC and (C and D) BC/Hap membranes showing the Hydroxyapatite deposition (lighter regions in the image) over the network of cellulose nanofibers.



Figure 2. EDS analysis showing the distribution of (B) Carbon, (C) Phosphorus and (D) $\mathrm{Ca}$ in the $\mathrm{BC} / \mathrm{Hap}$ surface. Spectra showing the main components present in $(\mathrm{E}) \mathrm{BC} / \mathrm{Hap}$ and $(\mathrm{F}) \mathrm{BC}$, demonstrating that the presence of $\mathrm{Ca}$ and $\mathrm{P}$ in $\mathrm{BC} / \mathrm{Hap}$ is due to the deposition process.
$\mathrm{C}, \mathrm{P}$ and $\mathrm{Ca}$ in the $\mathrm{BC} / \mathrm{Hap}$ surface $(\mathrm{B}, \mathrm{C}$ and $\mathrm{D}$, respectively). Also, the spectrum of the main components present in $\mathrm{BC} / \mathrm{Hap}$ and $\mathrm{BC}$ is showed (E and $\mathrm{F}$ ), demonstrating that the presence of $\mathrm{Ca}$ and $\mathrm{P}$ in $\mathrm{BC} /$ Hap composition is due to the deposition process.

\section{Macroscopic analysis}

There was no loss of any animal throughout the procedure and after surgery, and all animals had a great recovery. No animal showed pain condition after surgery.

After the euthanasia was performed, the dorsal region was shaved and a longitudinal incision was made in the direction of the spine (Figure 3) for the removal of the implanted biomaterials. Figure 3 shows the materials implanted subcutaneously 15 days post-surgery showing that the tissue response was not severe, without signs of necrosis and even infection. There are signs of inflammation such as slightly swollen areas, areas with hematoma due to trauma of the incision, which researchers consider a normal response.

\section{Microscopic analysis}

The qualitative microscopic analysis of the interface region with the implanted material shows that the progression along the period was similar in all materials studied.

After 7 days post-surgery (Figure 4A), in the adjacent region to the $\mathrm{BC}$, there is an intense inflammatory infiltrate $\left({ }^{*}\right)$, where polymorphonuclear cells and mononuclear cells are observed. Underlying the area of inflammatory infiltrate, a connective tissue (CT) ranging from loose to dense can be observed. After 15 days (Figure 4B), a decrease in the inflammatory infiltrate $\left.{ }^{*}\right)$ to moderate is noticed. It is also noticed a disorganized loose and vascularized connective tissue. In this image, a giant cell (GC) is showed, but they are rare, in general. After 60 days (Figure 4C), there is still the presence of a mild infiltrate $\left({ }^{*}\right)$, predominantly of mononuclear inflammatory cells. Permeating this area, there is a loose and connective tissue in organization process (CT), highly vascularized, with several fibroblasts between the lymphocytes and macrophages.

Similarly, in the samples analyzed 7 days after the implantation BC/ Hap (Figure 5A), there is an intense inflammatory infiltrate composed of polymorphonuclear and mononuclear cells, there is also a loose and disorganized connective tissue permeating the whole observed area (GT). After 15 days (Figure 5B), a large amount of mononuclear cells is observed in the inflammatory infiltrate $\left({ }^{*}\right)$. The adjacent connective tissue is still loose and disorganized. In the 60-day sample (Figure 5C), it

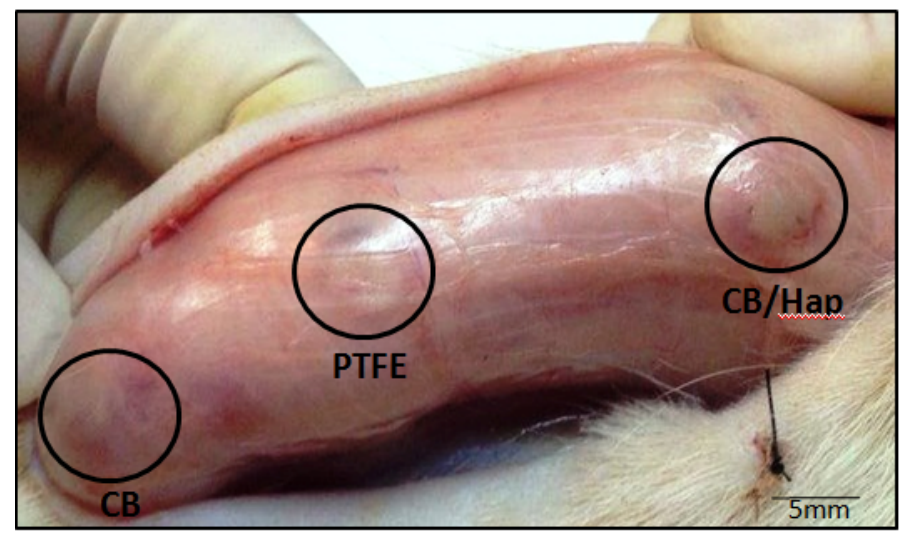

Figure 3. Materials (BC, BC/Hap and PTFE) implanted in the subcutaneous show, 15 days post-surgery, the tissue response was not severe, without signs of necrosis and infection. 


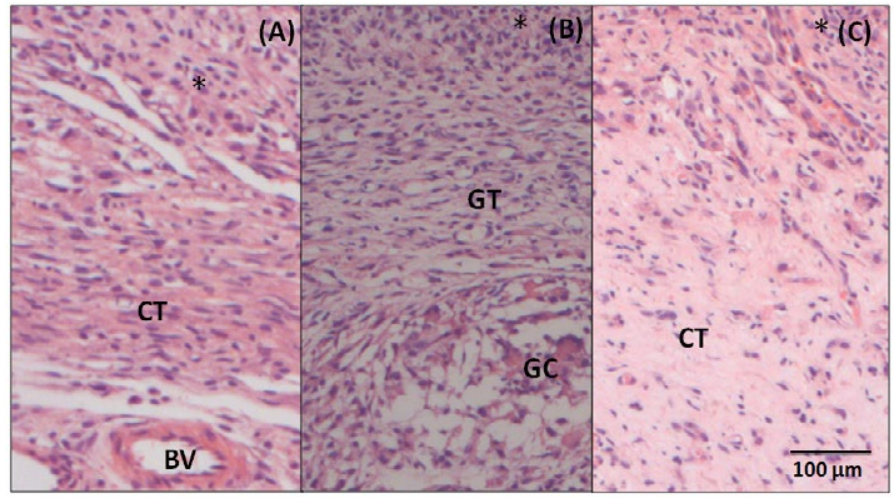

Figure 4. Photomicrography of the tissue adjacent to BC (A) 7-day post- surgery samples showing inflammatory infiltrate $(*)$, loose connective tissue (CT) and blood vessel (BV) (B) 15 - day post-surgery samples showing the granulation tissue (GT), inflammatory infiltrate ${ }^{*}$ ) and giant cell (GC) and (C) 60- day post-surgery, showing a connective tissue (CT) more organized in relation to previous period and mild inflammatory infiltrate. Hematoxylin and Eosin staining, 20X magnification.

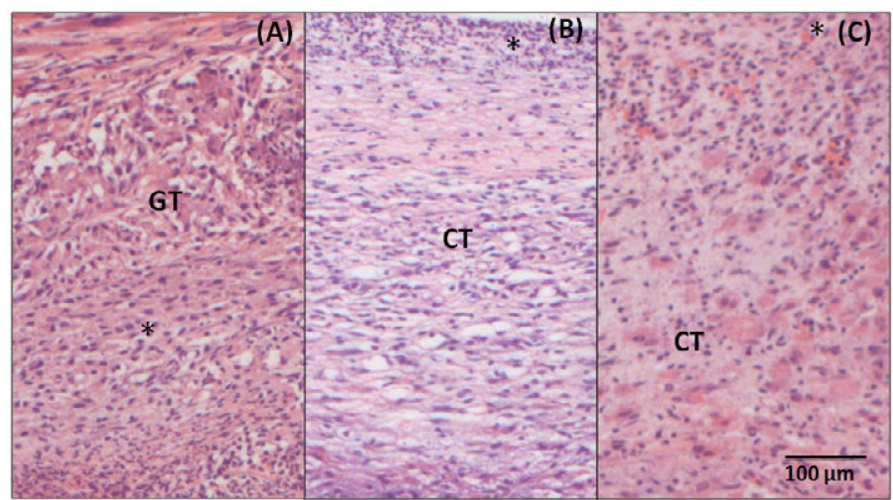

Figure 5. Photomicrography of the adjacent tissue to BC/Hap (A) 7-day post- surgery, showing inflammatory infiltrate $\left({ }^{*}\right)$ and granulation tissue (GT) (B) 15-day post-surgery, showing loose connective tissue (CT) and inflammatory infiltrate $\left({ }^{*}\right)$ and $(\mathrm{C}) 60$ - day post-surgery, showing a connective tissue $(\mathrm{CT})$ and a moderate inflammatory infiltrate $(*)$. Hematoxylin and Eosin staining, 20X magnification.

is still possible to observe a moderate inflammatory infiltrate. There are still some polymorphonuclear and mononuclear cells and a disorganized connective tissue.

The 7-day post-surgery sample with implantation of PTFE (Figure $6 \mathrm{~A})$ also presents an inflammatory infiltrate $\left(^{*}\right)$ in the interface area with the material (PTFE). Underlying the area of inflammatory infiltrate, it is possible to notice a loose and disorganized, but well vascularized connective tissue (CT). The 15-day sample (Figure 6B) presents a loose and vascularized connective tissue (CT) in the area of the implantation with inflammatory cells $\left({ }^{*}\right)$ permeating the connective tissue. In this image, unilocular adipose tissue (AT) is also observed underlying the area of the implantation. In the 60-day sample (Figure 6C), there is a dense and organized connective tissue (CT) with a large amount of fibroblast and mononuclear cells $\left.{ }^{*}\right)$ permeating the area.

Fibrous capsules were observed around all materials studied, as shown in Figure 7, for the samples collected 60 days post-surgery.

Figure 8 shows a Box-Plot (median and quartiles) representation of the number of mononuclear and polymorphonuclear inflammatory cells for comparing the response of each material in the same period of analysis. The same letters represent the groups which had statistically significant differences $(p<0.05)$ according to the Kruskal Wallis Test, followed by the Student Newman Keuls. Similarly, Figure 9 shows the Box-Plot representation for the analysis of the number of mononuclear and polymorphonuclear cells over time for each material. The same letters represent the groups which had statistically significant differences $(p<0.05)$ according to the Kruskal Wallis Test, followed by Student Newman Keuls.

In order to analyze the inflammatory pattern, the number of polymorphonuclear and mononuclear cells counted from each image was added. The average of the six images from each slice was then scored according to the classification already described, given in Table 1 , which also summarizes the results obtained. The values represent the number of slices in the score by the total number of slices examined according to the material and period of analysis.



Figure 6. Photomicrography of adjacent tissue to PTFE (A) 7- day post- surgery, showing loose connective tissue (CT) and inflammatory infiltrate $\left({ }^{*}\right)$ in the interface with the material (B) 15- day post-surgery, showing loose connective tissue (CT) and adipose tissue (AT) and (C) 60-day post-surgery, showing dense connective tissue (CT) with inflammatory cells $\left({ }^{*}\right)$. Hematoxylin and Eosin staining, 20X magnification.

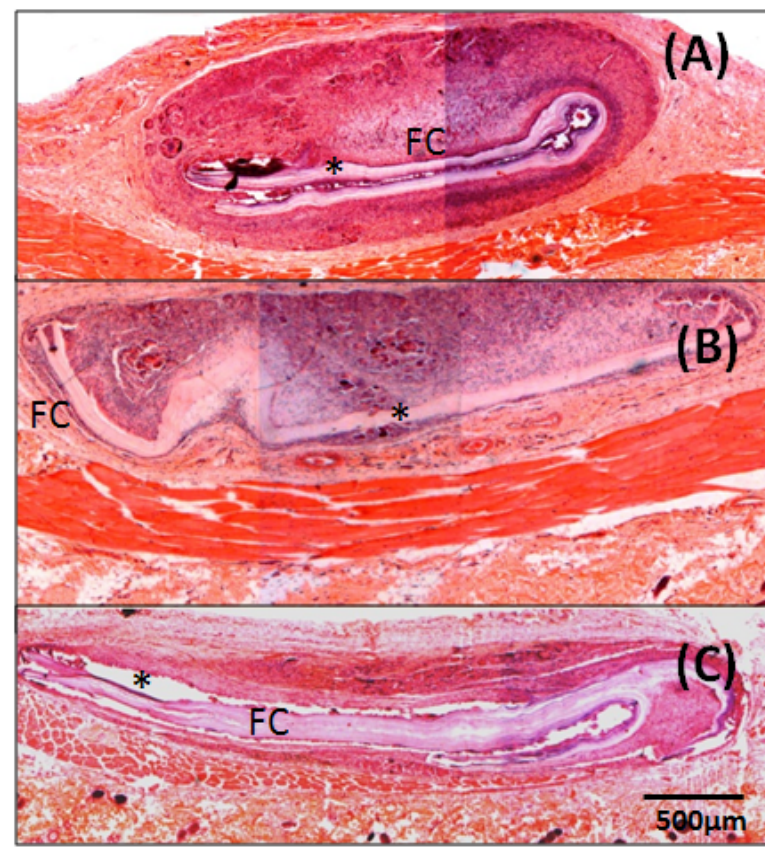

CB CBHap PTFE

Figure 7. Photomicrography of materials and tissue adjacent to them 60 days post-surgery, showing Fibrous Capsule (FC) around all materials. (A) BC, (B) BC/Hap, (C) PTFE. 
Table 1. Results of the morphometric analysis: The values represent the number of slices in the score by the total number of slices examined.

\begin{tabular}{|l|c|c|c|c|c|c|c|c|c|c|c|c|}
\hline & \multicolumn{9}{|c|}{ CB } & \multicolumn{4}{c|}{ CB/Hap } & \multicolumn{2}{c|}{ PTFE } \\
\hline & 0 & 1 & 2 & 3 & 0 & 1 & 2 & 3 & 0 & 1 & 2 & 3 \\
\hline 7 days & $0 / 6$ & $2 / 6$ & $4 / 6$ & $0 / 6$ & $0 / 6$ & $0 / 6$ & $6 / 6$ & $0 / 6$ & $0 / 6$ & $3 / 6$ & $3 / 6$ & $0 / 6$ \\
\hline 15 days & $0 / 6$ & $0 / 6$ & $6 / 6$ & $0 / 6$ & $0 / 6$ & $0 / 6$ & $6 / 6$ & $0 / 6$ & $0 / 6$ & $0 / 6$ & $6 / 6$ & $0 / 6$ \\
\hline 60 days & $0 / 6$ & $0 / 6$ & $6 / 6$ & $0 / 6$ & $0 / 6$ & $0 / 6$ & $6 / 6$ & $0 / 6$ & $0 / 6$ & $0 / 6$ & $6 / 6$ & $0 / 6$ \\
\hline
\end{tabular}


Figure 8. Box-Plot (median and quartiles) representation of the number of mononuclear and polymorphonuclear inflammatory cells in the tissue adjacent to each material after (A, B) 7 days, (C,D) 15 days and (E,F) 60 days post-surgery. The same letters represent a statistical difference ( $p<0.05$, Kruskal Wallis test, followed by Student Newman Keuls).

\section{Discussion and conclusion}

Bacterial Cellulose has attracted a great interest as a biomaterial [19] for a variety of biomedical applications such as skin healing in cases of burns [20,21], production of blood vessels [22,23], scaffolds for tissue engineering and bone repair $[7,8,24,25]$. Before the clinical use of new materials, their physicochemical and biological properties must be evaluated as any toxic components present in this material could cause irritation, degeneration or necrosis of the surrounding tissues. Thus, many studies perform their tests both in vivo and in vitro to test the inflammatory patterns and the biocompatibility $[11,13,26]$. The concept that any material that was completely inert in the body would be biocompatible has been reconsidered over time because it was verified that any material always triggers a response of the host tissue, usually represented by the formation of a fibrous capsule around it [5].

Since in vitro results are more limited in scope than the in vivo ones, in this study, in vivo experiments were used to evaluate the tissue reaction. For that purpose, $\mathrm{BC}, \mathrm{BC} / \mathrm{Hap}$ and $\mathrm{PTFE}$ were implanted in the subcutaneous tissue of rats and the tissue reaction was compared. This method is considered one of the most appropriate for this application [27,28]. In this study, the animal model and periods of observation were adopted according to the ISO-10993 [29] guidelines.

In all cases, the microscopic analysis revealed there is an inflammatory reaction in the initial periods, followed by chronic inflammatory features that evolve during the tissue regeneration (Figures 4,5 and 6). The counting of inflammatory cells showed a normal
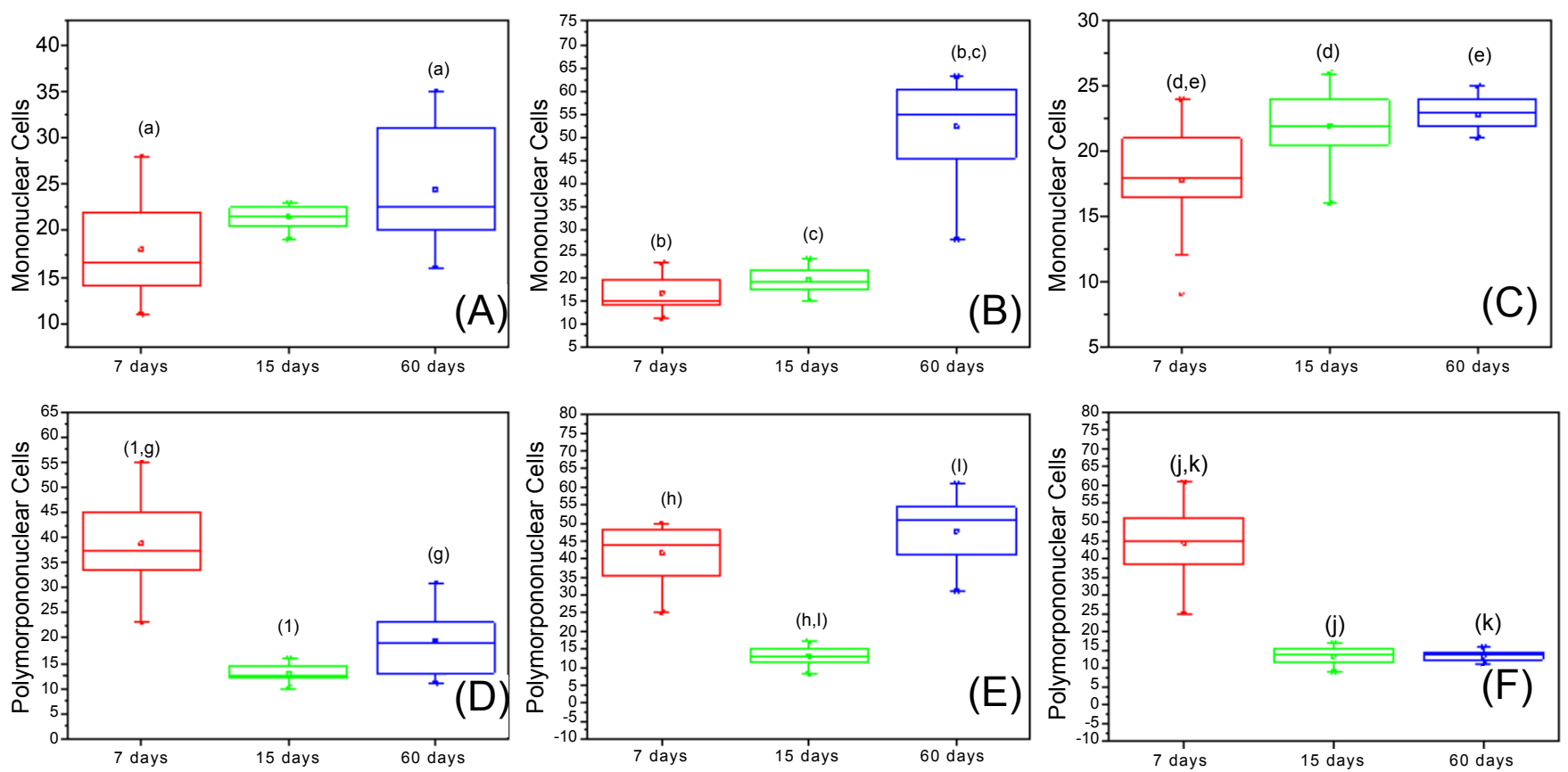

Figure 9. Box-Plot representation of the number of mononuclear cells (A) PTFE, (B) BC (C) BC/Hap and polymorphonuclear cells (D) PTFE, (E) BC (F) BC/Hap over the time. The same letters represent the results statistically different $(p<0.05$, Kruskal Wallis test, followed by Student Newman Keuls). 
inflammatory process, characterized by an increase of mononuclear cells (Figure 9A, B and C), a reduction of polimorphonuclear (Figures 9D, E and F) over time for all the materials studied ( $p<0.05$, KruskalWallis). The presence of polymorphonuclear cells in larger quantities, particularly observed in the earlier periods ( 7 and 15 days) for all tested materials, is expected in the initial processes of inflammation after an acute tissue aggression [13].

In some periods, the quantitative analysis showed differences regarding the number of inflammatory cells in the adjacent tissues when the $\mathrm{BC}$ and $\mathrm{BC} / \mathrm{Hap}$ were compared to the PTFE (Figure 8). However, when the severity (scores) of the inflammation was analyzed (Table 1), all materials showed no statistically significant differences when compared to the standard PTFE, commercial biocompatible materials ( $p>0.05$, Kruskal Wallis). After 15 and 60 days, all of them presented score 2 , which is a moderated reaction. Fibrous capsule is present around all materials after 60 days post implantation (Figure 7).

The reduction of inflammatory cells with the encapsulation of materials indicates the material implanted caused no aggression to tissues. The presence of giant cells was rare, another indication of normal reaction.

Saska et al. $[8,24]$ showed through in vitro studies that the bacterial cellulose is non-cytotoxic, mutagenic and it does not present a genotoxic action. BC promotes fibroblast proliferation and is responsible for the formation of extracellular matrix, which will allow healing. Thus, the results of this study complement prior studies, demonstrating that $\mathrm{BC}$ and $\mathrm{BC} / \mathrm{Hap}$ both present the same tissue reaction as the PTFE, proven to be a biocompatible material.

\section{Acknowledgment}

The authors thank FAPESP (São Paulo Research Foundation) for the scholarship granted to KVM and GOM.

\section{References}

1. Friedlaender GE (1987) Bone grafts. The basic science rationale for clinical applications. J Bone Joint Surg Am 69: 786-790. [Crossref]

2. Finkemeier CG (2002) Bone-grafting and bone-graft substitutes. J Bone Joint Surg Am 84-84A: 454-64. [Crossref]

3. Lindhe J, Karring T, Lang N. (1999) Tratado de periodontia clínica e implantodologia oral; Treaty of clinical periodontology and oral implantodologia. Guanabara Koogan.

4. Yin N, Chen S, Ouyang Y, Tang L, Yang J, et al. (2011) Biomimetic mineralization synthesis of hydroxyapatite bacterial cellulose nanocomposites. Progress in Natural Science: Materials International 21: 472-477.

5. Oréfice RL, de Magalhães Pereira M, Mansur HS (2006) Biomateriais: fundamentos e aplicações. Cultura Médica.

6. Zaborowska M, Bodin A, Bäckdahl H, Popp J, Goldstein A, et al. (2010) Microporous bacterial cellulose as a potential scaffold for bone regeneration. Acta Biomater 6: 25402547. [Crossref]

7. Ramani D, Sastry TP (2014) Bacterial cellulose-reinforced hydroxyapatite functionalized graphene oxide: a potential osteoinductive composite. Cellulose 21: $3585-3595$.

8. Saska S, Barud HS, Gaspar AM, Marchetto R, Ribeiro SJ, et al. (2011) Bacterial cellulose-hydroxyapatite nanocomposites for bone regeneration. Int $J$ Biomater: 175362. [Crossref]

9. Barros VM, Rosa AL, Beloti MM, Chierice G (2003) In vivo biocompatibility of three different chemical compositions of Ricinus communis polyurethane. J Biomed Mater Res A 67: 235-239. [Crossref]

10. Brasileiro Filho G. (1998) Bogliolo patologia geral. Guanabara Koogan.

11. Marques L, Holgado LA, Simoes RD, Pereira JD, Floriano JF, et al. (2013) Subcutaneous tissue reaction and cytotoxicity of polyvinylidene fluoride and polyvinylidene fluoridetrifluoroethylene blends associated with natural polymers. J Biomed Mater Res B Appl Biomater: 1284-1293. [Crossref]

12. Park JE, Barbul A (2004) Understanding the role of immune regulation in wound healing. Am J Surg 187: 11S-16S. [Crossref]

13. Parirokh M, Mirsoltani B, Raoof M, Tabrizchi H, Haghdoost AA (2011) Comparative study of subcutaneous tissue responses to a novel root-end filling material and white and grey mineral trioxide aggregate. Int Endod J 44: 283-289. [Crossref]

14. Anagnostou M, Chatzigianni E, Doucoudakis S, Potamianou A, Tesseromatis C (2009) Biocompatibility of resin composites subcutaneously implanted in rats with experimentally induced arthritis. Dent Mater 25: 863-7. [Crossref]

15. Zmener O, Pameijer CH, Kokubu GA, Grana DR (2010) Subcutaneous connective tissue reaction to methacrylate resin-based and zinc oxide and eugenol sealers. $J$ Endod 36: 1574-1579. [Crossref]

16. Principles of laboratory animal care. NIH Publ. 1985, 86-23.

17. Rasband WS, ImageJ US. Bethesda, Md, USA. ImageJ; 1997.

18. Yaltirik M, Ozbas H, Bilgic B, Issever H (2004) Reactions of connective tissue to mineral trioxide aggregate and amalgam. J Endod 30: 95-99. [Crossref]

19. Klemm D, Schumann D, Kramer F, Heßler N, Hornung M, Schmauder H-P, et al. (2006) Nanocelluloses as innovative polymers in research and application. Polysaccharides II: $49-96$.

20. Maneerung T, Tokura S, Rujiravanit R. (2008) Impregnation of silver nanoparticles into bacterial cellulose for antimicrobial wound dressing. Carbohydr Polym 72: 43-51.

21. Czaja W, Krystynowicz A, Bielecki S, Brown RM Jr (2006) Microbial cellulose--the natural power to heal wounds. Biomaterials 27: 145-151. [Crossref]

22. Andrade FK, Costa R, Domingues L, Soares R, Gama M. (2010) Improving bacteria cellulose for blood vessel replacement: Functionalization with a chimeric protein containing a cellulose-binding module and an adhesion peptide. Acta Biomater 6: 4034-4041. [Crossref]

23. Klemm D, Schumann D, Udhardt U, Marsch S. (2001) Bacterial synthesized celluloseartificial blood vessels for microsurgery. Prog Polym Sci 26: 1561-603.

24. Saska S, Scarel-Caminaga RM, Teixeira LN, Franchi LP, dos Santos RA, et al. (2012) Characterization and in vitro evaluation of bacterial cellulose membranes functionalized with osteogenic growth peptide for bone tissue engineering. J Mater Sci Mater Med 23 : 2253-66. [Crossref]

25. Tazi N, Zhang Z, Messaddeq Y, Almeida-Lopes L, Zanardi LM, et al (2012) Hydroxyapatite bioactivated bacterial cellulose promotes osteoblast growth and the formation of bone nodules. AMB Express 2: 61. [Crossref]

26. Viana Viola N, Maria Guerreiro-Tanomaru J, Ferreira da Silva G, Sasso-Cerri E, Tanomaru-Filho M, et al. (2012) Biocompatibility of an experimental MTA seale implanted in the rat subcutaneous: Quantitative and immunohistochemical evaluation. J Biomed Mater Res Part B Appl Biomater 7: 1773-1781.

27. Olsson B, Sliwkowski A, Langeland K (1981) Subcutaneous implantation for the biological evaluation of endodontic materials. J Endod 7: 355-367. [Crossref]

28. Safavi KE, Pascon EA, Langeland K (1983) Evaluation of tissue reaction to endodontic materials. J Endod 9: 421-429. [Crossref]

29. Biological evaluation of medical devices. Part2: Animal welfare requirements. ISO 10993-2: 2006

Copyright: (C2015 Massari KV. This is an open-access article distributed under the terms of the Creative Commons Attribution License, which permits unrestricted use, distribution, and reproduction in any medium, provided the original author and source are credited. 